\title{
Exploration and Practice of Innovative Ability Training of Master of Medicine under the Mode of Double Track Integration
}

\author{
Yan Li*, Bo Ling*, Yan-E Zhou, Longjian Huang, Xiaoqing Wen, Ying Zhang, Xianjiu Liao\#, \\ Qianli Tang\# \\ Youjiang Medical University for Nationalities, Baise, China \\ Email: " htmgx919@163.com, "1xj2006910@163.com
}

How to cite this paper: Li, Y., Ling, B., Zhou, Y. E., Huang, L. J., Wen, X. Q., Zhang, Y., Liao, X. J., \& Tang, Q. L. (2021). Exploration and Practice of Innovative Ability Training of Master of Medicine under the Mode of Double Track Integration. Creative Education, 12, 950-956. https://doi.org/10.4236/ce.2021.124068

Received: March 15, 2021

Accepted: April 27, 2021

Published: April 30, 2021

Copyright $\odot 2021$ by author(s) and Scientific Research Publishing Inc. This work is licensed under the Creative Commons Attribution International License (CC BY 4.0).

http://creativecommons.org/licenses/by/4.0/

\begin{abstract}
Objective: Explore the new mode of innovative ability training for master of medicine under the mode of double track integration. Methods: Based on the current situation of talent development for master of medicine under the mode of double track integration, it focuses on the difficulties and problems, and starts with the scientific research thinking, innovative consciousness, the integration of clinical and scientific research, construction of platform and faculty, and searches reasonable countermeasures to improve the innovative ability for master of medicine. Results: Under the mode of double track integration, it can be effectively integrated from the five dimensions of diversified training system, industry-study-research mode, double supervisor system, construction of discipline and experimental platform, teacher training and high-level talents to provide guarantee for the training of innovative ability of master of medicine. Conclusion: In view of the current situation of talent development for master of medicine under the mode of double track integration, it will provide a feasible direction for innovative ability training of master of medicine by deepening integration.
\end{abstract}

\section{Keywords}

Double Track Integration, Master of Medicine, Innovation Ability, Industry-Study-Research Mode, Minority Areas

\section{Introduction}

Master of medicine talents are high-level medical talents with excellent ability in

*These authors contributed equally to this work.

\#Corresponding author. 
clinical practice ability and scientific research, and become one of the major directions and mainstream trends of talent development in medical colleges and universities in China (Liu, Chen, Tao, \& Xu, 2020). In 2014, China gradually introduced the postgraduate training mode of "Double Track Integration" of professional degree training in medicine and resident standardized training.

Under the "Double Track Integration" mode, the master of medicine must meet the requirements of independent medical practice, and present thinking and insights in combination with clinical practice to become a doctor who can "treat the sick" and "research the sick" (Huang, Xu, Pang, \& Tang, 2020). However, master of medicine should work in clinical rotation at least 33 months during training, and it is required to obtain the certificates of doctor qualification and standardization training after strict assessment, which makes the students lack of exercise in scientific research and innovative ability training and subjective consciousness, and leads to the problem of insufficient innovative ability training of master of medicine (Zheng, Liu, Chen, Shi, Gu, \& Luo, 2017). This study will start from the current situation of talent development of master of medicine in medical colleges and universities, analyze the key factors, and find reasonable solutions and methods, thereby further promoting the training of innovation ability of medical postgraduates.

\section{Current Situation of Innovative Ability Training for Master of Medicine}

\subsection{Unsound System of Cultivation of Scientific Research Thinking}

Scientific research thinking is the foundation and the first step of the innovative ability training for master of medicine. Under the mode of double track integration, medical students need to focus on the professional courses within 3 months and work in clinical rotation for 33 months, thus leaving students a serious shortage of time to exercise thinking of scientific research (Chen, Li, Liu, Zhu, \& Fan, 2020). In the course system and clinical teaching process of students in some medical colleges, knowledge and clinical experience are often considered as the core content, which can meet the needs of clinical skills training of students, but hard to reconcile the cultivation of their scientific research thinking (Wu, Li, Feng, He, \& Li, 2020). Therefore, how to make full use of class, clinical teaching and other forms of education to form a sound system of cultivation of scientific research thinking has become one of the important contents of the current medical college education reform.

\subsection{Lack of Innovative Consciousness Guidance}

The lack of innovative consciousness is a common problem in master of medicine. There is a common view that master of medicine students pay more attention to clinical practice than scientific research, especially that mastery of excellent clinical knowledge and skills is the main component of their learning, which 
leads to difficulties in graduation thesis design, application of research projects, and acquisition of research results (Sun, Gan, Ye, Li, Jiang, Huang, \& Yang, 2021). How to correctly guide innovative consciousness of students and enhance their internal driving force in scientific research innovation is an important part of improving their innovation ability. Therefore, it has become one of the key directions in the cultivation of master of medicine in medical colleges and universities to introduce the innovative measures to enhance the internal driving force of innovation.

\subsection{Lack of Integration of Clinical and Scientific Research}

In the integration of clinical and scientific research, medical colleges and universities have been making efforts to promote and reform, but the effect is not ideal. In the training system for master of medicine, three links of theory, clinical teaching and scientific research always exist independently, and the knowledge system cannot be fully integrated, which makes the students suffer the cultivation of innovation ability (Chen, Li, Zheng, \& Lin, 2020). In particular, the innovation of master of medicine is often derived from clinical practice and combined with the scientific research system to achieve the output of its innovative achievements. Therefore, the lack of integration of clinical and scientific research is still an important bottleneck in the innovative ability training of master of medicine.

\subsection{Imperfect Platform Construction}

Insufficient and low-level discipline and experimental platform are the problems that general medical universities, especially local medical universities, have to face. In the case that the time for master of medicine to engage in scientific research is relatively limited, the problem of insufficient discipline and experimental platform will be more prominent. Faced with a tight experimental platform in a limited time, students' interest in scientific research and research progress will be greatly hindered (Xu, Chen, \& Chen, 2019). The promotion of the construction of discipline and experimental platform has become a task that all medical universities must attach great importance to.

\subsection{The Cultivation of Teaching Staff Needs to Be Improved}

Supervisor is the first person responsible for the training of the masters of medicine, and shoulders the important task of training clinical skills and innovation ability for them. In the innovative ability training of master of medicine, supervisors and teachers are the main guides and instructors. The level of teaching staff in medical universities affects the students' clinical skills and scientific research innovation (Zhang, 2020). However, the shortage of high-level talents, heavy clinical tasks and other restrictive factors generally exist in the teaching staff of medical universities, which cannot provide all-round assistance for the training of master of medicine. Therefore, to speed up the construction of 
teaching staff and improve the level of teachers has become the focus of medical universities.

\section{Innovative Measures}

\subsection{Implementing Diversified Training System to Enhance Students' Scientific Research Thinking}

Scientific research thinking is formed by students in long-term study, scientific research and practice. In the cultivation of scientific research thinking for the master of medicine, it should be based on the whole process of postgraduate study and carried out from theoretical learning, clinical practice, scientific research and other aspects. Therefore, it is of theoretical basis and practical significance to adopt a diversified training system. For theoretical teaching, various forms such as the introduction of scientific research cases into teaching and the training of scientific research thinking after class can be implemented to integrate theoretical knowledge and scientific research thinking, so as to lay a foundation for the cultivation of scientific research thinking of master of medicine (Tian, Jiang, Yang, Mi, \& Li, 2019). For clinical teaching, the group meeting, seminar and joint consultation can be used to let students participate in the study and discussion of diagnosis and treatment of difficult diseases, so as to cultivate students' innovative thinking in scientific research of clinical practice ( $\mathrm{Zhu}, \mathrm{Shi}$, \& Li, 2019). For scientific research, the whole closed-loop management should be implemented in order to further deepen and promote the cultivation of students' innovative thinking in scientific research. And strict management should be adopted in the aspects of students' proposal, experiment, group meeting, mid-term report, graduation dissertation and so on (Ni, Guo, Wang, \& Ding, 2020). Based on theoretical learning, clinical practice and scientific research, the implementation of a diversified training system will comprehensively improve the scientific research thinking of master of medicine.

\subsection{Promoting Students' Consciousness of Innovation by Industry-Study-Research Mode}

The lack of students' consciousness of innovation is caused by the students' insufficient cognition of the connotation, function and significance of scientific and technological innovation. Under the double track integration, most of the masters of medicine concentrate on the study of clinical knowledge and skills, and do not understand the role of innovation in national education, health and clinical practice, thus resulting in their weak consciousness of innovation. The industry-study-research mode effectively integrates the resources of universities, hospitals, research institutes and enterprises. Through field visits, academic conferences, scientific and technological cooperation and other forms, students can participate in multiple aspects of scientific and technological innovation, personally understand the connotation and importance of innovation, so as to comprehensively enhance their consciousness of innovation and promote the 
source power of scientific research innovation (Li \& Zeng, 2017).

\subsection{Double Supervisor System Can Promote the Deep Integration of Clinical and Scientific Research}

The supervisors of master of medicine are usually doctors with senior clinical titles, and they usually have rich clinical experience and high-level scientific research attainments. However, due to the busy clinical and teaching affairs, they have spent a lot of time in the clinical teaching of students, but they cannot spare more time in scientific research to help students comprehensively improve their innovation ability. The effective promotion of double supervisor system is to add a second supervisor on the basis of a clinical supervisor, so that the clinical supervisor can be fully responsible for students' clinical knowledge and skills, the second supervisor is responsible for students' scientific research skills, and the two supervisors jointly develop students' training methods, so as to realize the effective integration of clinical and scientific research (Xu, Xie, \& Chen, 2016). The implementation of the double supervisor system will promote the deep integration of clinical practice and scientific research, so as to truly achieve the purpose of "scientific research comes from clinical practice and promotes clinical practice", and at the same time meeting the training goal of masters of medicine, and make them become doctors who can "treat the sick" and "research the sick".

\subsection{Acceleration of the Construction of Disciplines and Experimental Platforms}

The construction of disciplines and experimental platforms is the cornerstone of various medical colleges and universities for talent development. Integrating intramural resources of talent, equipment, experimental conditions and material, medical colleges and universities can focus on platform construction so as to promote the number and level of platforms (Tong, Chen, Ding, \& Gu, 2020). Disciplines and experimental platforms will provide students with the necessary conditions for various scientific research and innovation such as experimental sites, experimental equipment, experimental skills, topics declaration, achievement acquisition, etc., thus providing a strong guarantee for the innovative ability training of master of medicine.

\subsection{Simultaneous Introduction and Training of High-Level Faculty}

The construction of teaching staff is one of the core contents to ensure the innovative training of master of medicine. The cultivation of academic level and scientific research and innovation ability of master of medicine depends on the careful cultivation of tutors, and the quality of teaching staff has become the key to ensure the quality of talent development various medical colleges and universities. The competition for talents in major medical colleges and universities is becoming more and fiercer. It has become one of the effective ways to increase 
the introduction of high-level talents and the training of teachers simultaneously (Hu, Huang, \& Sun, 2020). To train the teachers, outstanding talents in the college and university can be dispatched to excellent universities, hospitals and research institutes at home and abroad for further study, thus improving the level of the original teaching staff. Simultaneously, medical colleges can take the initiative to attract outstanding talents at home and abroad, so as to improve the level of teaching staff and provide teacher guarantee for the talent development of master of medicine.

From what has been discussed above, aiming at the current situation of ineffective cultivation of the innovative ability of medical masters, we start from scientific research thinking, innovative consciousness, the integration of clinical and scientific research, platform and faculty construction to find reasonable countermeasures. Under the Mode of Double Track Integration, medical colleges can carry out deepening reform in five aspects: diversified training system to enhance scientific research thinking, production, education and research mode to enhance students' innovative consciousness, dual tutorial system to promote the integration of clinical and scientific research, acceleration of the construction of disciplines and experimental platforms, and simultaneous teachers training and introduction of high-level talents so as to improve the innovation ability of master of medicine as a whole.

\section{Fund Program}

Innovation Project of Guangxi Postgraduate Education (Project No.: JGY2020170, JGY2019161, JGY2021214, JGY2021219).

\section{Conflicts of Interest}

The authors declare no conflicts of interest regarding the publication of this paper.

\section{References}

Chen, J., Li, D., Liu, X., Zhu, X., \& Fan, X. (2020). Research on Improving the Training Quality of Innovative Talents for Master of Clinical Medicine under the Background of "Double First-class" Construction. Science, Education and Literature (Late Edition), No. 3, 88-90.

Chen, X., Li, N., Zheng, Z., \& Lin, M. (2020). The Effects of Coordination between Medical Education and Medical Care on the Scientific Research Abilit of Clinical Medicine Graduate Students and Strategies To Counter Those Effects. China Higher Medical Education, No. 12, 5-7.

Hu, L., Huang, H., \& Sun, W. (2020). Practice and Exploration of Introducing High-Level Talents in Provincial Universities under the Background of "Double First-class". Intelligence, No. 35, 130-131.

Huang, L., Xu, Y., Pang, G., \& Tang, G. (2020). Research on Standardization of Medical Specialized Master Training Based on "Double Track Integration" Model. Guangxi Education, No. 3, 117-119.

Li, G., \& Zeng, Y. (2017). Analysis and Research on the Current Situation of Innovative Talent 
Development in Western Local Medical Colleges under the "Industry-University-Research" Mode-Based on the Investigation of the "Industry-University-Research" Talents Development Mode in Western X Medical University. China Higher Medical Education, No. 12, 38-39.

Liu, J., Chen, S., Tao, Y., \& Xu, Z. (2020). Analysis on Improving the Training Mode of Master's Degree in Military Medicine According to the Requirements of Competency. Southwest National Defense Medicine, 30, 351-353.

Ni, G., Guo, N., Wang, Q., \& Ding, J. (2020). Discussion on the Cultivation of Scientific Research Ability of Postgraduate Students Majoring in Clinical Medicine-Taking a Grade-Three Hospital in Anhui Province as an Example. Journal of Youjiang Medical College for Nationalities, 42, 123-125.

Sun, Y., Gan, S., Ye, R., Li, R., Jiang, E., Huang, J., \& Yang, C. (2021). Investigation and Analysis of Learning Status of Postgraduates with Master's Degree in Clinical Medicine. Health Vocational Education, 39, 114-115.

Tian, G., Jiang, W., Yang, C., Mi, J., \& Li, Y. (2019). Research Driven Training Mode for Medical Academic Postgraduates. Education Teaching Forum, No. 13, 196-200.

Tong, N., Chen, J., Ding, X., \& Gu, H. (2020). Construction and Exploration of Secondary Scientific Research Sharing Platform in Medical Colleges and Universities. Science and Technology Information, 18, 1-4+8.

Wu, X., Li, B., Feng, Y., He, D., \& Li, L. (2020). Cultivation of Scientific Research Ability of Master of Stomatology in the Mode of Double Track Integration. China Continuing Medical Education, 12, 63-65.

Xu, L., Xie, X., \& Chen, J. (2016). Exploration of Dual Tutorial System for Master Postgraduate Students Majoring in Clinical Medicine in Medical Colleges. Basic Medical Education, 18, 590-592.

$\mathrm{Xu}$, T., Chen, D., \& Chen, Z. (2019). Research on the Cultivation of Scientific Research Ability of Postgraduate Students Majoring in Clinical Medicine under "Four Certificates in One". Journal of Fujian Medical University (Social Science Edition), 20, 44-47.

Zhang, J. (2020). Research on the Construction of Evaluation Index System for the Training Quality of Postgraduates Majoring in Clinical Medicine under the Background of Medical and Educational Cooperation Level. Jinzhong: Shanxi Medical University.

Zheng, Y., Liu, S., Chen, J., Shi, J., Gu, Y., \& Luo, Z. (2017). Analysis on "Dual Track in One” Training Mode for Professional Degree Postgraduates in Resident Doctor Standardized Training-Take a Top Three Hospital as an Example in Yunnan Province. Soft Science of Health, 31, 32-35.

Zhu, F., Shi, Q., \& Li, Z. (2019). Discussion on Improving the Scientific Research literaCy of Postgraduates Majoring in Clinical Medicine. Basic Medical Education, 21, 836-837. 